\title{
Thermal and Spectroscopic Studies of Polyvinyl Alcohol/Sodium Carboxy Methyl Cellulose Blends.
}

\author{
A. M. Shehap \\ Physics Department. Faculty of Science, Cairo University, Giza, Egypt.
}

Films of polyvinyl alcohol (PVA), sodium carboxy methyl cellulose homopolymer and their blends of composition 0.7/0.3, 0.5/0.5, 0.3/0.7 (wt/wt) were prepared using cast technique. The influence of blend composition of PVA/NaCMC has been investigated by thermo-gravimetric analysis (TGA) and IR and UV/VIS spectra. From TGA and its derivative DTGA it was found that the thermal stability of the blend samples is increased with increasing NaCMC content. The kinetic parameters such as activation energy, entropy, enthalpy and free energy in the first and second decomposition steps based on thermo gravimetric data were determined. The IR studies indicated that PVA/NaCMC are miscible in the full composition range. The apparent degree of crystallinity of each polymer is decreased with increasing content of the blending partner in most samples. The analysis of the UV/VIS spectra provided an evidence for miscibility conformed by the absorption edge and the band tail. Sample 0.5/0.5 (wt/wt) PVA/ NaCMC is the most optimum miscible blend one.

\section{Introduction:}

Blends of polymers represent class of materials with better mechanical properties and biocompatibility than those of single components [1, 2]. An important and determined aspect of the blend is the miscibility of the component. When two polymers undergo miscibility, well order microstructure result, which give the blend unique certain physical properties according to the formation of micro phase configuration. The resulting micro phase configuration can induce pronounced changes in various properties different from homopolymers. Miscibility in polymer blends is assigned to specific interaction between polymers component, which usually give rise to a negative free energy of mixing in spite of the high molecular weight of polymers.

Polyvinyl alcohol (PVA) has received a great deal of attention due to its considerable applications [3-9] either pure or composite with other materials. The optical uses of PVA are concerned with the retardation polarization and filtration of light and with photography [9]. Sodium carboxy methyl cellulose 
NACMC is widely used in different field ranges from technological industries to the biological, pharmaceutical, petroleum and medical fields [10-13].

Blending NaCMC with another flexible, synsetic polymer such as PVA seems to be an attractive way for improving properties of the film. The determination of the thermal properties of solids is very important factor for a varity of technological application. This information can help in the understanding the structure of solid and their behavior and in the indirect calculation of related properties, sometimes difficult to obtain experimentally. The IR spectroscopy has proved to be valuable tool to provide information on the specific groups found in the blend composition as well as the polymerpolymer interaction [1]. Also, UV/VIS analysis gives an evidence for understanding energy band diagram and optical parameters which is relatively affected by processing conditions.

In this work thermo-gravimetric analysis (TGA) and IR and UV/VIS spectra of PVA/ NaCMC films were used in order to reveal amount of information about miscibility and changes in various properties of the blends.

\section{Experimental:}

Both PVA and NaCMC of molecular weight 14000 and 4500 were supplied by BDH chemical LTD (Poole, UK). The degree of hydrolysis of PVA is $98.5 \%$ to $100 \%$. The components with different weight percentage were dissolved in a mixture of distillated water and ethanol with ratio 4:1. Complete dissolution was obtained using a magnetic stirrer at room temperature for $8 \mathrm{hr}$. Films of appropriate thickness $(0.05 \mathrm{~mm})$ were cast in stainless steel Petri dishes and dried in an air oven at $40{ }^{\circ} \mathrm{C}$. The thermal analysis (TGA) was carried out using SHIMADZU TGA-50H, SHIMADZU Corporation, KYOTO Japan. The heating rate used for all samples under investigation was $10{ }^{\circ} \mathrm{C} / \mathrm{min}$ from room temperature to $400{ }^{\circ} \mathrm{C}$ under nitrogen atmosphere with flow of $30 \mathrm{ml} / \mathrm{min}$. The infra red spectral analysis was carried out using PYE UNICAN spectrophotometer over the range 400 to $4000 \mathrm{~cm}^{-1}$. The UV/VIS absorption spectra were measured in the wavelength 200 to $800 \mathrm{~nm}$ using BERKIN ELMER 4B spectrophotometer.

\section{Results and Discussion:}

\subsection{Thermal Properties:}

Thermogravimetric analysis is a process in which substance is decomposed in the presence of heat which causes bonds within the molecule to be broken. TGA plays an important role in determining thermal stability of the material. TGA curves and their derivatives of PVA and NaCMC and their blends are indicated in Fig. (1). The TGA curves show that the thermal stability of the blend samples lies 
in between those of the two individual homopolymers and the degradation is completed in two steps. These steps are distinguishable in the diagram of mass loss (TGA\%) during heating as well as -more clearly-in the diagram of derivative mass loss (DTG ). All of the samples show a small (5.69-12.28 \%) mass loss for the first decomposition step and more significant (52.80-63.69 \%) for the second step.

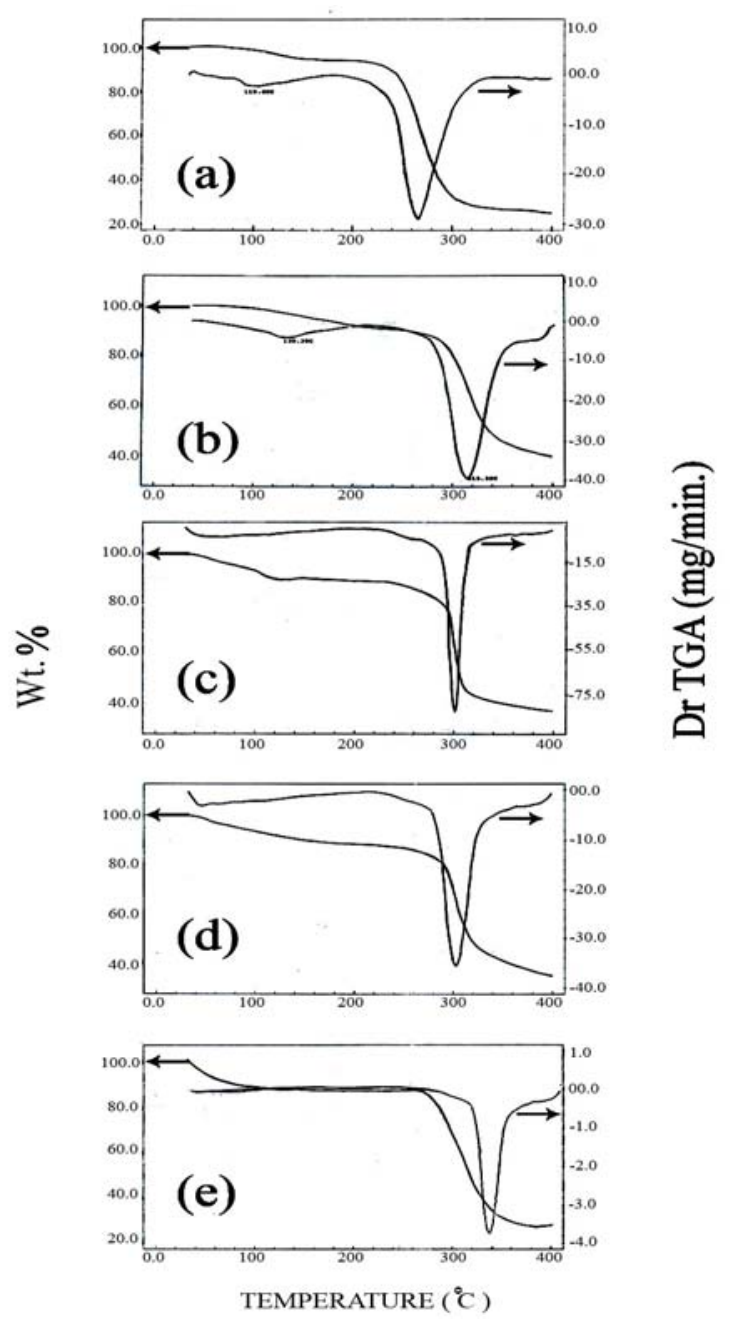

Fig. (1): TGA \& DrTGA of PVA/NaCMCs blend sample:

(a) $1.0 / 0.0$, (b) $0.7 / 0.3$, (c) $0.5 / 0.5$, (d) $0.3 / 0.7$ and (e) $0.0 / 1.0$ (wt/wt\%). 
Table (1) represents the decomposition steps and percentage mass loss for individual polymers and their blends. The lower values of percentage mass loss in the first decomposition step may be due to splitting or volatilization of small molecule, and/or the evaporation of residual absorbed water [14]. These lower values of mass loss enables one to suggest that the phase transition observed indicate the existence of physical transition. The latter process in TGA curves covers a wider temperature range $\left(150-399^{\circ} \mathrm{C}\right)$, which includes the melting point of PVA - as physical transition and the thermal degradation of the samples. Therefore the higher values of mass loss in second decomposition step indicate the existence of chemical degradation process [15] resulting from bond scission (carbon-carbon bonds) in the polymeric backbone. DTGA curves show two temperature broad peaks Tp's corresponding to the first and second decomposition regions (see Table (1)). It is to be noted that the peak temperature of the main degradation step is shifted to higher temperatures compared to pure PVA with the increasing of $\mathrm{NaCMC}$ concentration but still lower than pure $\mathrm{NaCMC}$. This is an indication that $\mathrm{NaCMC}$ is more stable than PVA and that the chemical structure plays an important role in the thermal decomposition process.

Table (1): TG and DTGA data for PVA/ NaCMC blend samples.

\begin{tabular}{|c|c|c|c|c|c|c|}
\hline \multirow{2}{*}{$\begin{array}{c}\text { PVA/ NaCMC } \\
(\mathrm{wt} / \mathrm{wt})\end{array}$} & \multirow{2}{*}{$\begin{array}{c}\text { Region of } \\
\text { decomposition }\end{array}$} & \multicolumn{3}{|c|}{ Temperature $\left({ }^{\circ} \mathrm{C}\right)$} & \multicolumn{2}{|c|}{ Weight loss $(\%)$} \\
\cline { 3 - 7 } & & start & End & $\mathrm{Tp}^{*}$ & Partial & Total \\
\hline $1.0 / 0.0$ & $1^{\text {st }}$ & 39 & 161 & 119 & 5.69 & 75.62 \\
& $2^{\text {nd }}$ & 161 & 398 & 266 & 69.36 & \\
\hline $0.7 / 0.3$ & $1^{\text {st }}$ & 38 & 180 & 115 & 7.29 & 60.76 \\
& $2^{\text {nd }}$ & 181 & 398 & 315 & 53.35 & \\
\hline $0.5 / 0.5$ & $1^{\text {st }}$ & 34 & 160 & 105 & 10.22 & 63.1 \\
& $2^{\text {nd }}$ & 161 & 399 & 318 & 52.80 & \\
\hline $0.3 / 0.7$ & $1^{\text {st }}$ & 34 & 157 & 90 & 10.26 & 64.95 \\
& $2^{\text {nd }}$ & 158 & 399 & 325 & 54.66 & \\
\hline $0.0 / 1.0$ & $1^{\text {st }}$ & 33 & 149 & 75 & 12.28 & 75.95 \\
& $2^{\text {nd }}$ & 150 & 399 & 345 & 63.60 & \\
\hline
\end{tabular}

Tp*: Peak temperature of DTGA 
The thermodynamics activation parameters of the decomposition process were evaluated by making use of the well known Coats -Redfern equation [16] in the form:

$$
\ln \left[\frac{-\ln (1-\alpha)}{T^{2}}\right]=-\frac{E}{R T}+\ln \frac{A R}{\beta E}
$$

where $\mathrm{A}$ is constant, $\beta$ is heating rate, $\mathrm{R}$ is universal gas constant, $\alpha$ is fraction of decomposition and $\mathrm{E}$ is the activation energy. Therefore, plotting $\ln \left[\frac{-\ln (1-\alpha)}{T^{2}}\right]$ against $1 / \mathrm{T}$ according to equation 1 should give a straight line whose slope is directly proportional to the activation energy $-\frac{E}{R}$. The activation entropy $\Delta \mathrm{S}$, the activation enthalpy $\Delta \mathrm{H}$, and the free energy (Gibbs function $\Delta \mathrm{G}$ ) were calculated using the following equations [17]:

$$
\begin{aligned}
\Delta S & =2.303\left(\log \frac{A h}{k T}\right) R \\
\Delta H & =E-R T \\
\Delta G & =\Delta H-T \Delta S
\end{aligned}
$$

where $\mathrm{k}$ and $\mathrm{h}$ are Boltzmann and Planck constants respectively, $\mathrm{T}$ is the temperature involved in the calculation selected as the peak temperature of DTGA. The entropy $\Delta \mathrm{S}$ gives information about the degree of order of the system, the enthalpy $\Delta \mathrm{H}$ gives information about the total thermal motion and Gibbs or free energy gives information about the stability of the system.

Figures ( $2 \& 3)$ represent the Coats-Redfern plots of the first and second decomposition steps, respectively, for individual polymers and their blend samples. An obtained value of about 0.90 to 0.99 for $\mathrm{R}^{2}$ (correlation factor) indicates a good correlation for both decomposition steps. The calculated thermodynamic parameters values are given in Table (2). It is clear that the values of thermodynamic parameters $\mathrm{E} \Delta \mathrm{S}^{\prime} \Delta \mathrm{H}$, and $\Delta \mathrm{G}$ in both decomposition steps for $\mathrm{NaCMC}$ are less than PVA and the blend samples. Thus, it can be concluded that the nature of NaCMC is low bonding strength orderness, relatively low thermal motion, and relative thermal stability with respect to other samples. Among the blends the sample of composition $0.5 / 0.5 \mathrm{wt} / \mathrm{wt}$ showed lowest activation energy this may be due to bond weakening effects as a result of mixing PVA with NaCMC. Also, it is to be mentioned that the values of $\mathrm{E}, \Delta \mathrm{S}, \Delta \mathrm{H}$, and $\Delta \mathrm{G}$ in the first decomposition step are less than those of the second decomposition step. The lower values of activation energies at the initial stages are most likely associated initiation process that occurs at weak linkage of PVA and NaCMC. By increasing the temperature random scission of macromolecules chains predominates and the activation energy has greater value. 


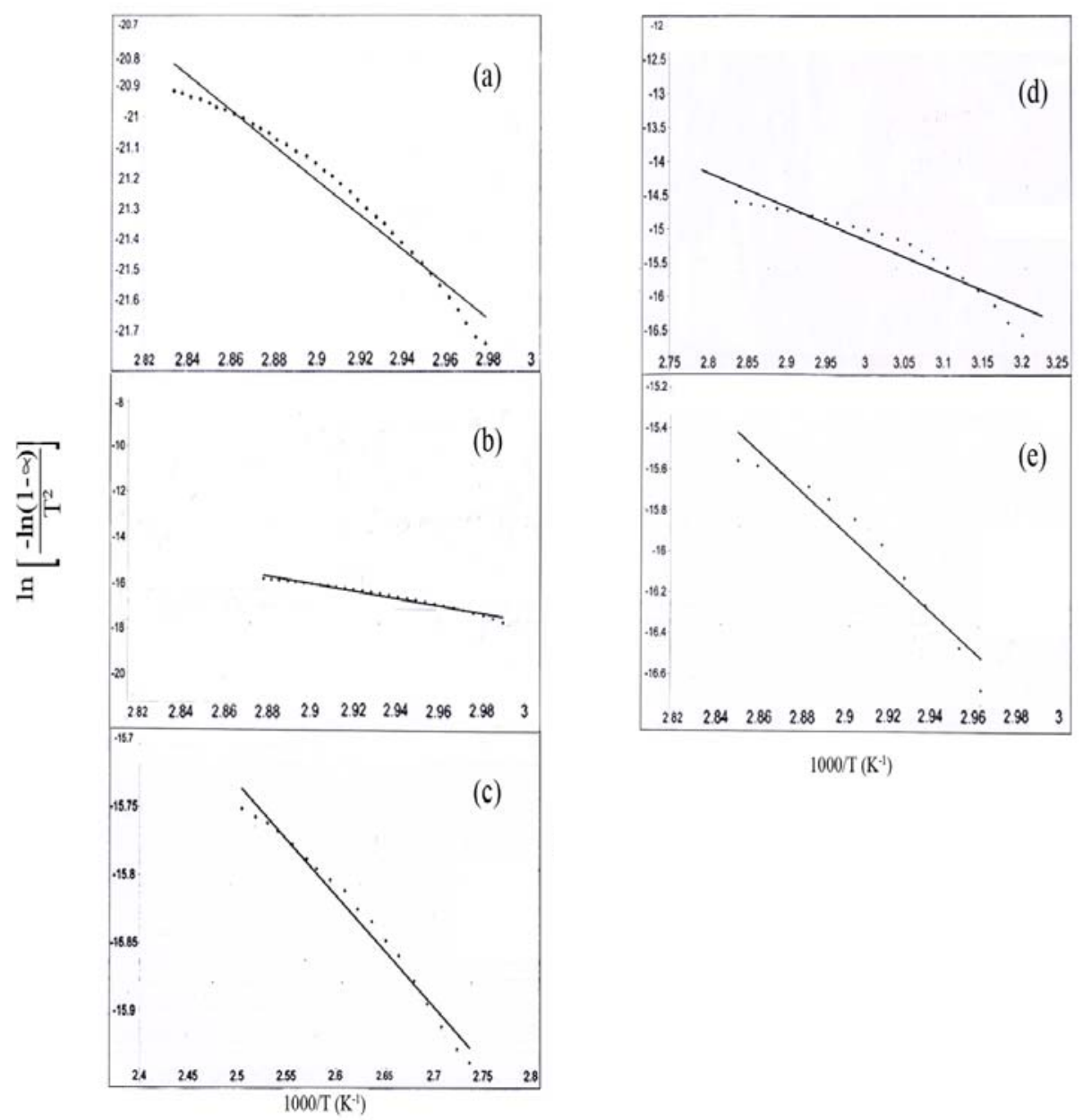

Fig. (2): Coats-Redfern plots of the first decomposition step for blend samples:

(a) $1.0 / 0.0$, (b) $0.7 / 0.3$, (c) $0.5 / 0.5$, (d) $0.3 / 0.7$ and (e) $0.0 / 1.0$ (wt/wt $\%$ ).

Table (2): Thermodynamic parameters for PVA/NaCMC blend samples.

\begin{tabular}{||c||c|c|c|c|c|c|c|c||}
\hline \multirow{2}{*}{$\begin{array}{c}\mathrm{PVA} / \mathrm{NaCMC} \\
(\mathrm{wt} / \mathrm{wt})\end{array}$} & $\begin{array}{c}\mathrm{E}(\mathrm{KJ} / \mathrm{gm} . \mathrm{mole}) \\
1^{\text {st }}\end{array}$ & $\begin{array}{c}2^{\text {nd }} \\
\text { region }\end{array}$ & $\begin{array}{c}1^{\text {st }}(\mathrm{KJ} / \mathrm{mole}) \\
\text { region }\end{array}$ & $\begin{array}{c}2^{\text {nd }} \\
\text { region }\end{array}$ & $\begin{array}{c}\Delta \mathrm{H}(\mathrm{KJ} / \mathrm{mole}) \\
1^{\text {st }}\end{array}$ & $\begin{array}{c}2^{\text {nd }} \\
\text { region }\end{array}$ & $\begin{array}{c}1^{\text {st }} \\
\text { region }\end{array}$ & $\begin{array}{c}2^{\text {nd }} \\
\text { region }\end{array}$ \\
\hline \hline $1.0 / 0.0$ & 34.84 & 43.25 & -245.7 & -278.2 & 31.82 & 38.17 & 121.0 & 208.3 \\
\hline $0.7 / 0.3$ & 41.06 & 73.44 & -290.9 & -300.9 & 38.46 & 70.80 & 132.2 & 160.8 \\
\hline $0.5 / 0.5$ & 31.76 & 40.08 & -358.0 & -371.0 & 29.43 & 35.30 & 138.5 & 249.1 \\
\hline $0.3 / 0.7$ & 42.38 & 70.60 & -271.7 & -291.0 & 39.70 & 65.80 & 126.8 & 233.8 \\
\hline $0.0 / 1.0$ & 31.00 & 34.35 & -190.0 & -240.0 & 29.10 & 30.01 & 82.6 & 154.4 \\
\hline \hline
\end{tabular}



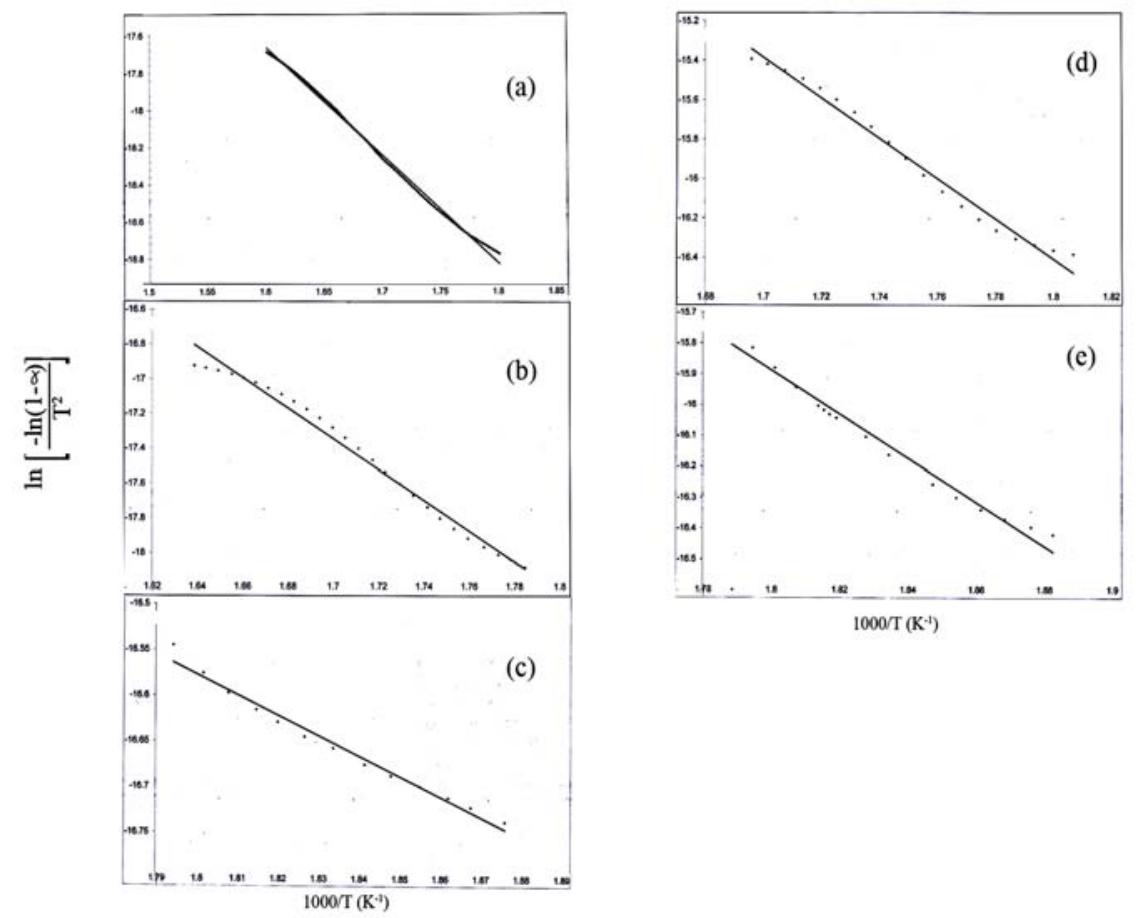

Fig. (3): Coats-Redfern plots of the second decomposition step for blend samples: (a) $1.0 / 0.0$, (b) $0.7 / 0.3$, (c) $0.5 / 0.5$, (d) $0.3 / 0.7$ and (e) $0.0 / 1.0(w t / w t \%$ ).

\subsection{Infrared Spectroscopy (IR):}

Figure (4) shows the Infrared spectrum and assignment of the most evident absorption bands for pure PVA thin films between 500 and $4000 \mathrm{~cm}^{-1}$. The spectrum seems to be consistent with that previously reported in literature [18-22] except the appearance of absorbed $v_{\delta}(\mathrm{HOH})$ bending band [23] at 1660 $\mathrm{cm}^{-1}$. Water is probably present since vacuum drying is not used. A relatively broad and intense $v(\mathrm{OH})$ absorption stretching band is observed between $(3220$ $-3448) \mathrm{cm}^{-1}$, indicating the presence of polymeric association of the free hydroxyl groups and bonded OH stretching vibration [24, 25]. In general the IR absorption bands of PVA are all quite broad and severally overlapped in the $600-1500 \mathrm{~cm}^{-1}$ region. There are several reasons for this behaviour, where half of the bulk PVA consists of crystallites embedded in a matrix of glassy material. The difference of symmetry between PVA molecule and in the glass is expected to contribute to two sets of frequencies to the IR spectrum. Slight shift between equivalent frequencies in the two phases undoubtely contributes to the overlapping. There must also exist regions of intermediate crystalinity, and the crystalline region themselves have a mixed symmetry due to the random placement of hydroxyl groups along the chain .As well known, the hydroxyl 
bands are always strongly broadened in hydrogen bonded alcohol, properly as a result of a very pronounced anharmonicity of vibrations .Furthermore O-Hplane bending motion is coupled strongly with other molecular motions that involve frequencies in the range $600-1500 \mathrm{~cm}^{-1}$. The broad $\mathrm{O}-\mathrm{H}$ absorption stretching vibration is observed a round $3430 \mathrm{~cm}^{-1}$ for PVA results from the superposition of multiple polymeric $\mathrm{H}$ bonds associated with the crystalline phase and dimeric $\mathrm{H}$ bonds associated with the amorphous phase [26]. Nuclear magnetic resonance [27] has shown that PVA possesses an "intermediate" region in addition to the usual crystalline and amorphous phases. Such an intermediate phase has been identified in other polymers, and played a significant role in the hydration of PVA [28].

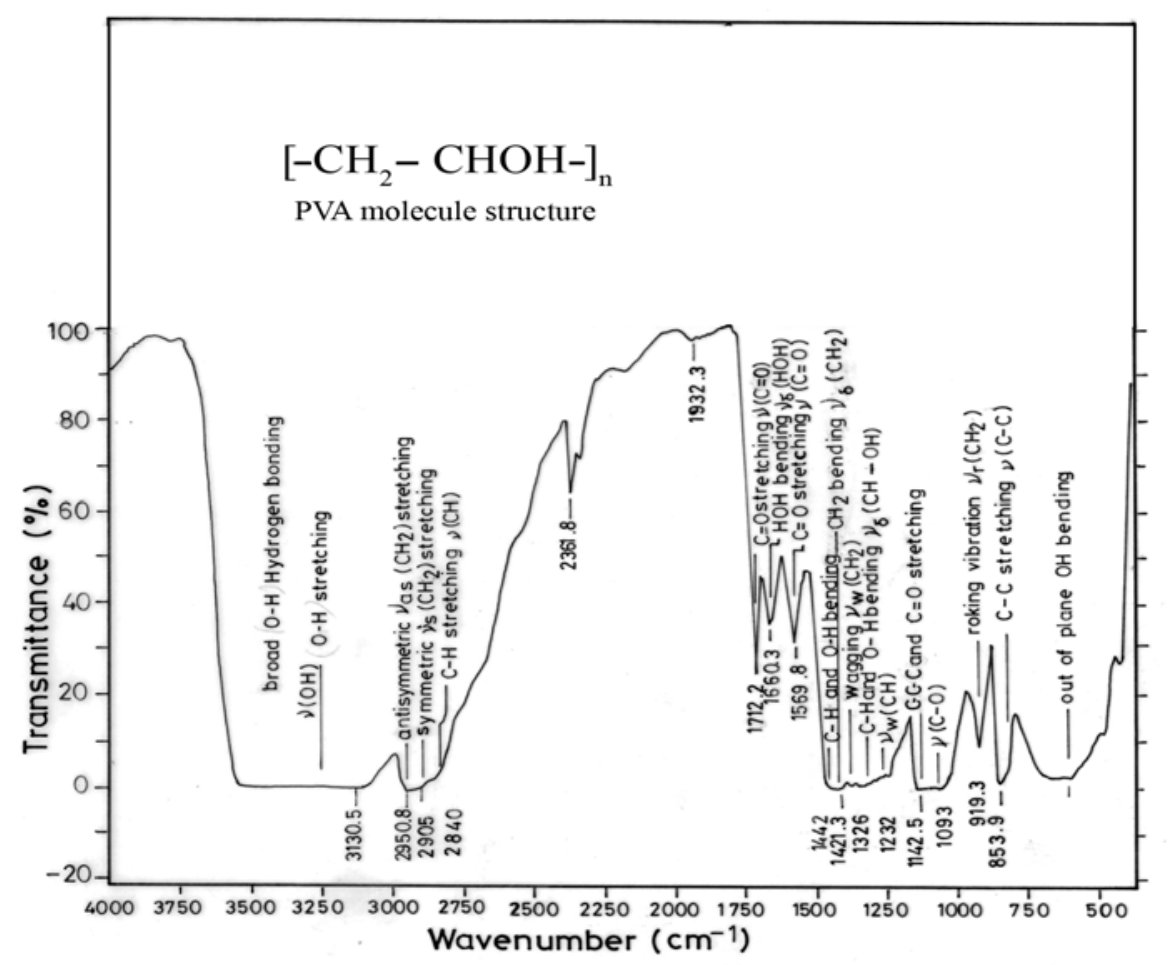

Fig. (4): IR spectra of PVA.

Two distinct absorption bands occurring at 2950 and $2905 \mathrm{~cm}^{-1}$ resulted from anti-symmetric $v_{\text {as }}\left(\mathrm{CH}_{2}\right)$ and symmetric $v_{\mathrm{s}}\left(\mathrm{CH}_{2}\right)$ stretching bands of $\mathrm{CH}_{2}$ groups respectively. Also, the shoulder like band at $2840 \mathrm{~cm}^{-1}$ has been assigned as $v(\mathrm{CH})$ stretching vibration. The bands at 1712 and $1570 \mathrm{~cm}^{-1}$ of the carbonyl group are due to absorption of the residual acetate groups due to the manufacture of PVA from hydrolysis of polyvinyl acetate [29, 30]. The symmetric bending mode $v_{\delta}\left(\mathrm{CH}_{2}\right)$ is found at $1432 \mathrm{~cm}^{-1}$. The band at about 1326 and $1232 \mathrm{~cm}^{-1}$ results from wagging vibration of $\mathrm{CH}_{2}$ and $\mathrm{CH}$ respectively. 
The stretching band at $1142 \mathrm{~cm}^{-1}$ is known to be crystallization-sensitive band of PVA and is taken as a measure of the degree of crystallinity [31]. In addition, the $1142 \mathrm{~cm}^{-1}$ band inferred that it might be due to a kind of absorption mechanism related to the presence of oxygen atom [32]. The band at about 1093 $\mathrm{cm}^{-1}$ is assigned to $v(\mathrm{C}-\mathrm{O})$ stretching vibration of the ether group [33]. The band at $919 \mathrm{~cm}^{-1}$ has been related to syndiotactic structure and is assigned to $v_{\mathrm{r}}\left(\mathrm{CH}_{2}\right)$ rocking vibration. The bands at 854 and $611 \mathrm{~cm}^{-1}$ are assigned to $v$ (C-C) stretching vibration and out of plane $\mathrm{OH}$ bending respectively.

The IR spectrum of the most evident absorption bands for NaCMC in the wavelength range of $400-4000 \mathrm{~cm}^{-1}$ is shown in Fig.(5). A broad and intense $v$ $(\mathrm{OH})$ band is observed in the $3000-3700 \mathrm{~cm}^{-1}$ region, which indicates the presence of a broad range of associated hydroxyls. Absorption bands at 2929and $2887 \mathrm{~cm}^{-1}$ labeled $v\left(\mathrm{CH}_{2}\right)$ and $v(\mathrm{CH})$ are due to methylene $\mathrm{CH}_{2}$ and $\mathrm{CH}$ stretching vibrations, respectively. The presence of strong absorption band at about $1619 \mathrm{~cm}^{-1}$ confirms the presence of carboxylate anion (COŌ)[34,35]. The bands around 1416 and $1325 \mathrm{~cm}^{-1}$ are assigned to $-\mathrm{CH}_{2}$ scissoring and $\mathrm{OH}$ bending vibration respectively. The $\mathrm{CH}$ bending absorption band at 1372 $\mathrm{cm}^{-1}, v_{\delta}(\mathrm{CH})$, is assumed to be a crystalline of $\mathrm{NaCMC}$ similar to that found in cellulose [36]. The ether group C-O bands appeared at 1114 and $1000 \mathrm{~cm}^{-1}$ are due to stretching vibration of secondary alcohol $v(\mathrm{C}-\mathrm{O})$. In addition, the bands appeared at 900 and $727 \mathrm{~cm}^{-1}$ correspond to the $C_{1}$ group frequency ( $\beta$ - glucosidic linkage), and $\mathrm{OH}$ out-of- plane bending, vibration of hydroxyl group respectively [36].

The possibility of interactions between the polymer pair in the blending form through specific polar groups is examined using IR analysis. Fig. (6) shows the full spectra $\left(500-4000 \mathrm{~cm}^{-1}\right)$ of $0.7 / 0.3,0.5 / 0.5,0.3 / 0.7$ (wt/wt) PVA/NaCMC blends. Since these two polymers possess some similar functional groups, therefore the group regions of IR spectra are partially the same and their spectra differ only in the finger print regions. The blends comprising both components show spectra with characteristic of both but the vibrational bands characterizing each polymer are predominating as its content increases. 


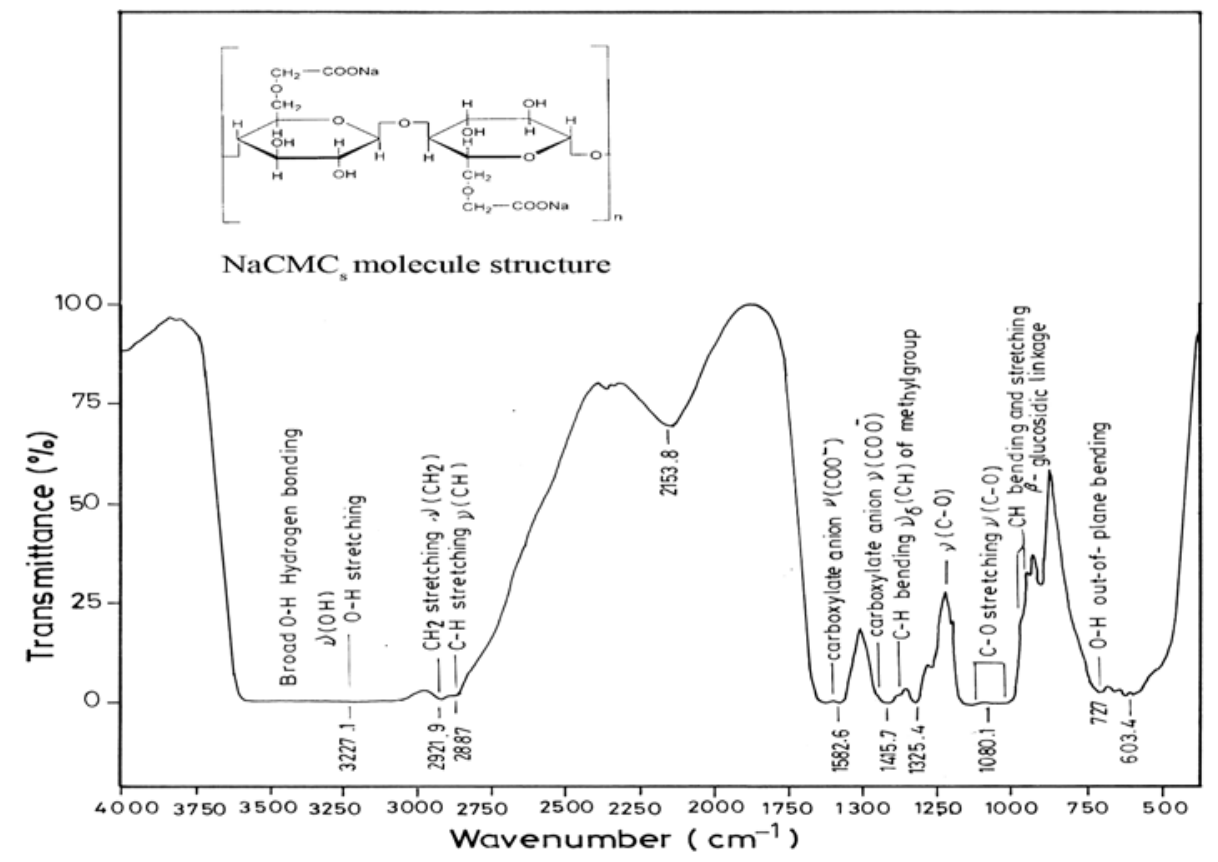

Fig. (5): IR spectra of $\mathrm{NaCMCs}$.

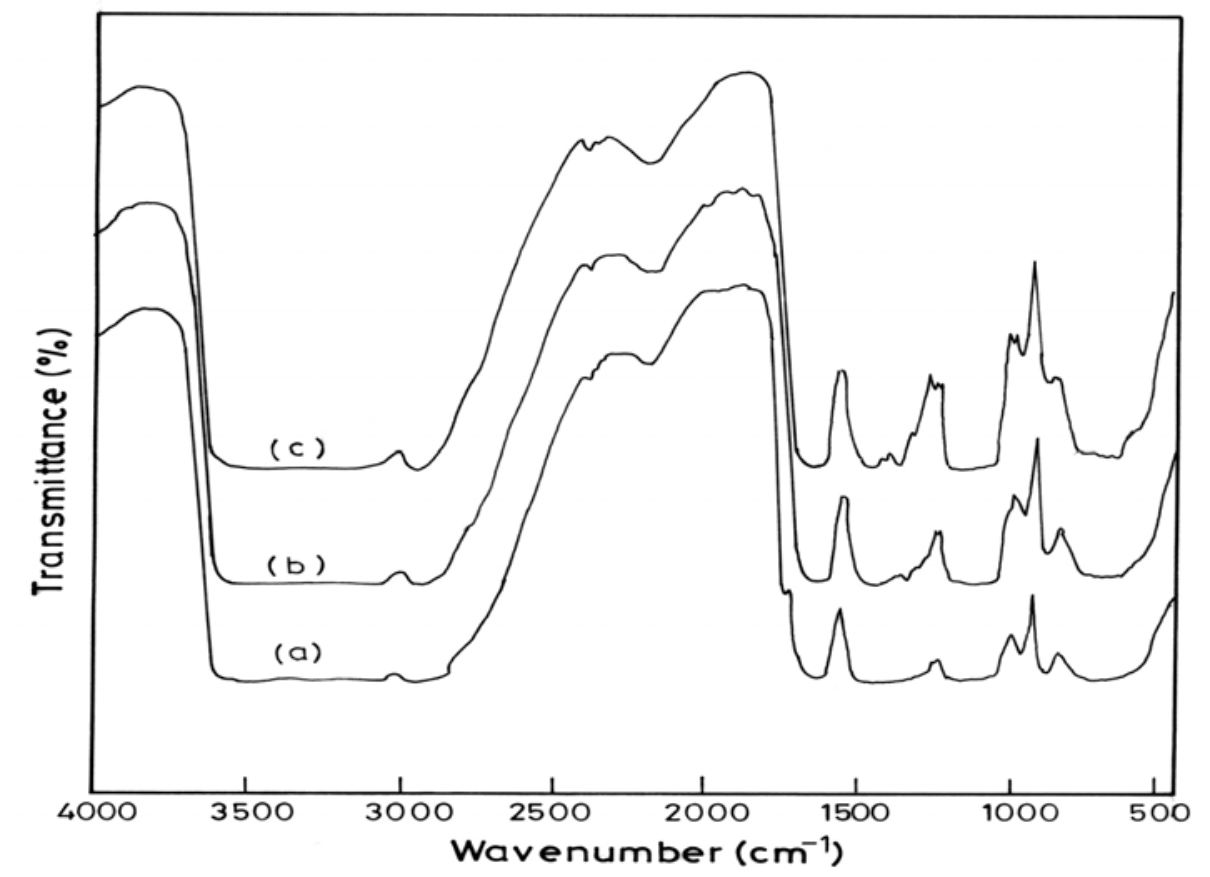

Fig. (6): IR spectra of PVA/NaCMCs blend samples: (a) $0.7 / 0.3$, (b) $0.5 / 0.5$ and (c) $0.3 / 0.7(\mathrm{wt} / \mathrm{wt})$. 
The shape of the carbonyl band $\mathrm{C}=\mathrm{O}$ for $0.7 / 0.3$ (wt/wt) PVA/ $\mathrm{NaCMC}_{\mathrm{s}}$ blend is different from that of PVA indicating change in the balance of free associated carbonyl group. The $\beta$ - glucosidic group that only exist in $\mathrm{NaCMC}$ is shifted by about $40 \mathrm{~cm}^{-1}$ in the blend samples. In addition the crystalline bands $v(\mathrm{c}-\mathrm{c}), v_{\delta}(\mathrm{CH})$ for PVA and $\mathrm{NaCMC}$ are shifted by about 25 and $30 \mathrm{~cm}^{-1}$ respectively. These results may indicate that there should occur a strong hydrogen bond interaction between $-\mathrm{OH}$ and $-\mathrm{CH}_{2}-\mathrm{O}-\mathrm{CH}_{2} \mathrm{COONa}$ in $\mathrm{NaCMC}$ and $-\mathrm{OH}$ groups in PVA in the blend samples. Consequently, it seems reasonable to assume the miscibility of PVA/ NaCMC blends in the full composition range.

The indices of crystallinity of PVA ( $\left.\mathrm{I}_{\mathrm{PVA}}\right)$ and $\mathrm{NaCMC}_{\mathrm{s}}\left(\mathrm{I}_{\mathrm{NaCMC}}\right)$ in pure and blend films can be calculated according to the following equations [37].

$$
\begin{gathered}
\mathrm{I}_{\mathrm{PVA}}=\mathrm{A}_{1142} / \mathrm{A}_{2905} \\
\mathrm{I}_{\mathrm{NaCMC}}=\mathrm{A}_{1372} / \mathrm{A}_{2887}
\end{gathered}
$$

where $A_{1142}$ and $A_{1372}$ are the absorbance of crystallization sensitive bends of PVA $v(\mathrm{C}-\mathrm{C})$ and $\mathrm{NaCMC}_{s} v_{\delta}(\mathrm{CH})$ respectively. In addition $\mathrm{A}_{2905}$ and $\mathrm{A}_{2887}$ are the absorbance of $v_{\mathrm{s}}\left(\mathrm{CH}_{2}\right)$ and $v(\mathrm{CH})$ bands of PVA and NaCMC, respectively. Figure (7) shows the variation of $\mathrm{I}_{\mathrm{PVA}}$ and $\mathrm{I}_{\mathrm{NaCMC}}$ as a function of weight percent of PVA compound in the samples. It is clear from this figure that the indices of crystallinity of both components decrease by mixing, except a very small increasing observed for $0.7 \mathrm{wt}$ of PVA content blend sample .It must be mentioned that the decrease of the index of crystallinity of NaCMC through the blends is higher than that of PVA.

\subsection{UV/VIS Spectra:}

Figure (8) shows the absorption spectra of both PVA and NACMC homopolymers and their blends $0.7 / 0.3,0.5 / 0.5$ and $0.3 / 0.7(\mathrm{wt} / \mathrm{wt}) \mathrm{PVA} /$ NACMC .It is clear that there is no absorption band in the visible region for all the investigated samples since the films are transparent. The absorbance values of the blend samples of 0.7 and 0.3 weight PVA content are lower than individual polymers through range $200-800 \mathrm{~nm}$ while the absorbance values for 0.5 wt PVA content blend sample has an contrary behaviour. The spectra of the individual polymers exhibit two absorption bands, a shoulder like band a round $275 \mathrm{~nm}$ and hump at $330 \mathrm{~nm}$, which are related to high energy absorption. These bands are assigned to existence of chromophoric carbonyl groups [37] It is reasonable to assign the absorption bands at $275 \mathrm{~nm}$ and $330 \mathrm{~nm}$ to the electronic transitions $\pi-\pi^{*}$ (k-band) and $n-\pi^{*}$ (R band), respectively. The 
spectra of the all blend samples contain only a remarkable shoulder like band with an irregular small deviation in position. The disappearance of the absorption band at $330 \mathrm{~nm}$ in the blend sample provides evidence for the miscibility between homopolymers.

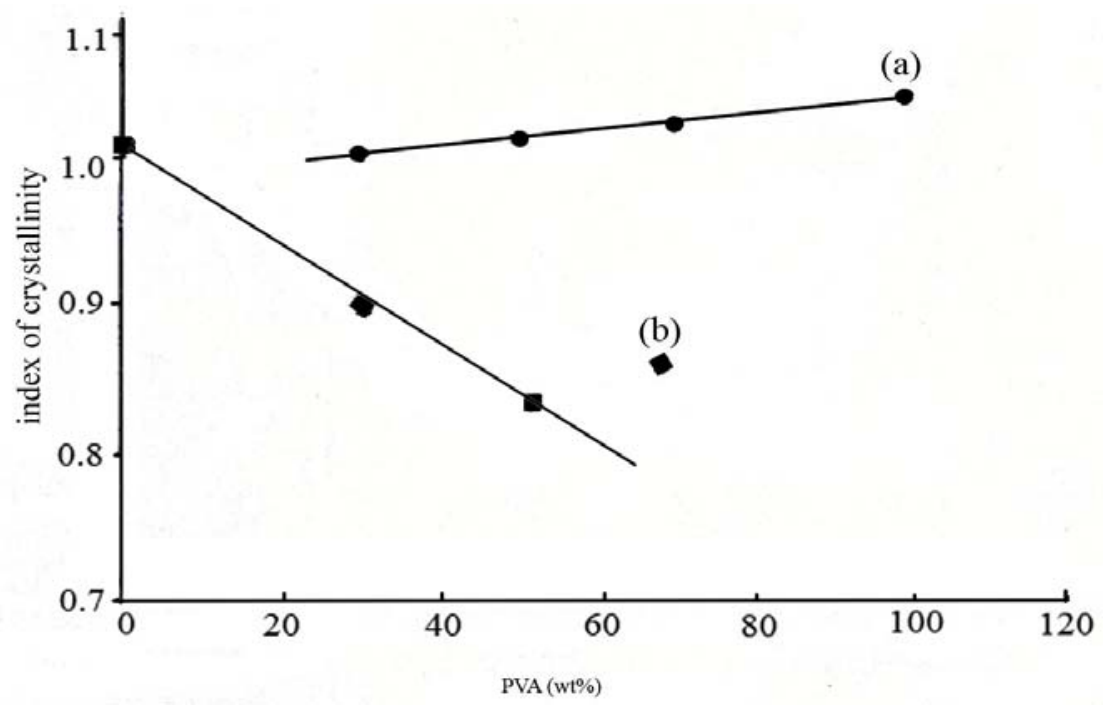

Fig. (7): Composition dependence of the indices of the crystallinity: (•) PVA and ( $\bullet$ ) NaCMC.

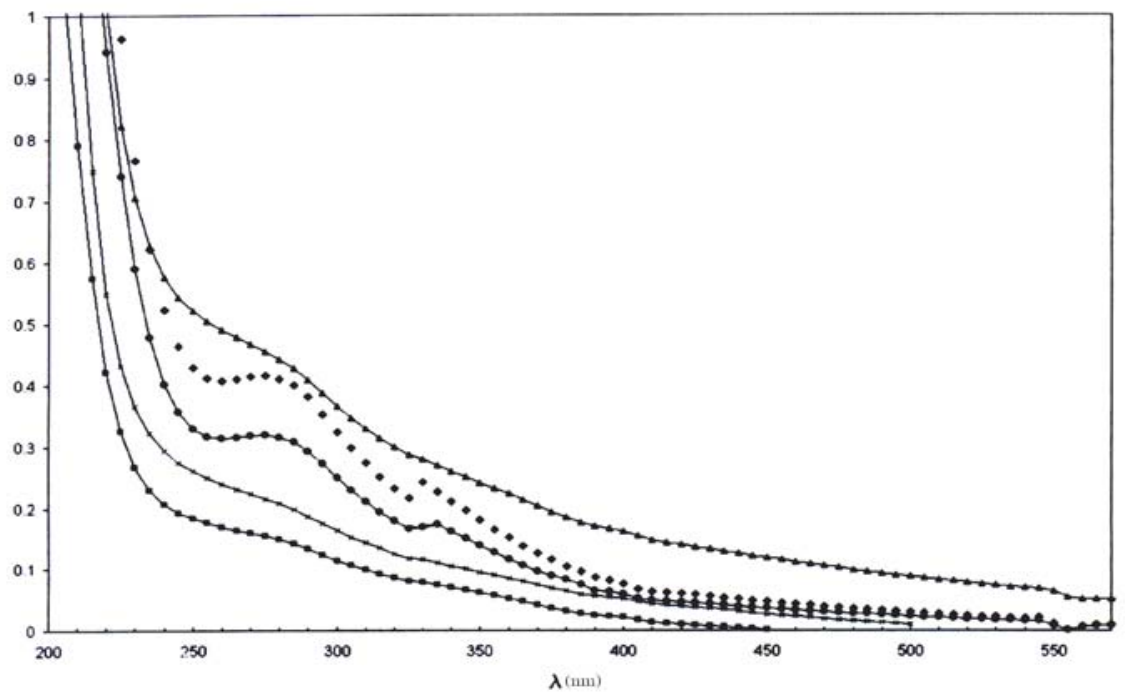

Fig. (8): The relation between absorbance (A) versus wavelength $(\lambda)$ for PVA/ NaCMC: $(\bullet)$ 1.0/0.0, (曰) 0.7/.03, ( $\mathbf{\Delta}) 0.5 / 0.5,(\mathrm{x})$ and $(\bullet) 0.0 / 1.0(\mathrm{wt} / \mathrm{wt})$. 
The absorption coefficient $\alpha(v)$ of the optical absorption can be calculated from the relation,

$$
\alpha(v)=\frac{A}{d}
$$

where $\mathrm{d}$ is thickness of the sample while $\mathrm{A}$ is the absorbance. The calculated values of absorption coefficient are relatively small $\left(10-160 \mathrm{~cm}^{-1}\right)$ as in most low carrier concentration semi-crystalline materials. Thus the films under investigation are considered weakly absorbing.

Figure (9) shows the plot of the absorption coefficient with the incident photon energy for individual PVA, NaCMC and their blends. The $\alpha(v)$ relation exhibits step rise near the absorption edge and a straight line relationship is observed in the high $\alpha$ region. The extrapolation of the linear portion of the curves to the abscissa has been used to find the values of the absorption edge. The values are listed in Table (3). It is clear that the values of the absorption edge for the blend samples are less than those for pure polymers, This may reflect the induced changes in the number of available final states according to blend composition. In addition, the blend sample of $0.5 / 0.5 \mathrm{wt} / \mathrm{wt} \mathrm{PVA} / \mathrm{NaCMC}$ has the minimum absorption edge $(2.5 \mathrm{eV})$ indicating that it is the most proper conduction as compared to other samples.

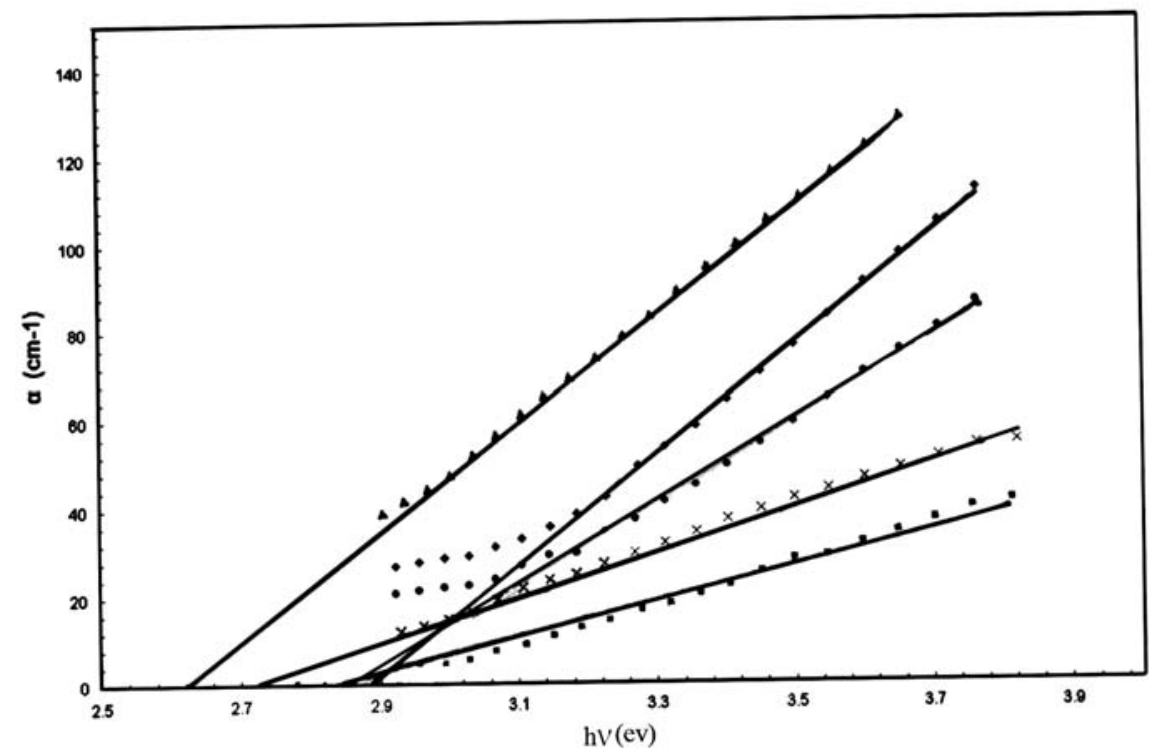

Fig. (9): The relation between absorbance coeffecient $(\alpha)$ versus hu for PVA/ NaCMC:

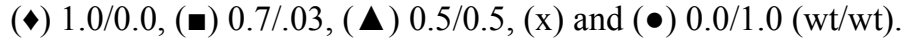


Table (3): Values of absorption edge and energy tail of PVA/ NaCMC blend samples.

\begin{tabular}{|c|c|c|}
\hline PVA/ NaCMCs (wt/wt) & Absorption edge (eV) & Energy tail (eV) \\
\hline $1.0 / 0.0$ & 2.82 & 0.70 \\
\hline $0.7 / 0.3$ & 2.78 & 0.64 \\
\hline $0.5 / 0.5$ & 2.51 & 0.88 \\
\hline $0.3 / 0.7$ & 2.71 & 0.65 \\
\hline $0.0 / 1.0$ & 2.90 & 0.78 \\
\hline
\end{tabular}

The absorption coefficient $\alpha(v)$ of the optical absorption near the band edge for many amorphous and crystalline materials show an exponential dependence on photon energy $\mathrm{h} v$ given by the formula proposed by Urbach [38]

$$
\alpha(v)=\alpha_{o} \exp \left(\frac{h v}{\Delta E}\right)
$$

where $\alpha_{\mathrm{o}}$ is constant and $\Delta \mathrm{E}$ is the width of the band tails of localized states in normally forbidden band gap that associated with the amorphous nature of the materials.

Figure (10) shows the relation between $\operatorname{Ln} \alpha$ and $h v$ for individual polymers and their blend samples. The values of band tails $\Delta \mathrm{E}$ are calculated from the slopes of these lines as shown in Fig. (10) and listed in Table (3). It is clear that the values of $\Delta \mathrm{E}$ for blend samples are nearly close together and lie between $0.64-0.88 \mathrm{eV}$. The tails are sensitive to structure and disorder levels generated in the system [39] .The formation of polymer -polymer blends is known to induce tails in the density of states by perturbing the band edge via a deformation potential, coulomb interaction and by forming localized band stats. The values of $\Delta \mathrm{E}$ obtained vary slightly with composition but in an irregular trend. Among these samples, the value of $\Delta \mathrm{E}$ for $0.5 / 0.5$ (wt/wt) PVA/NaCMC blend sample is the highest one, reflecting that it has a high degree of disorder, so one can consider it as the most miscible blend. 


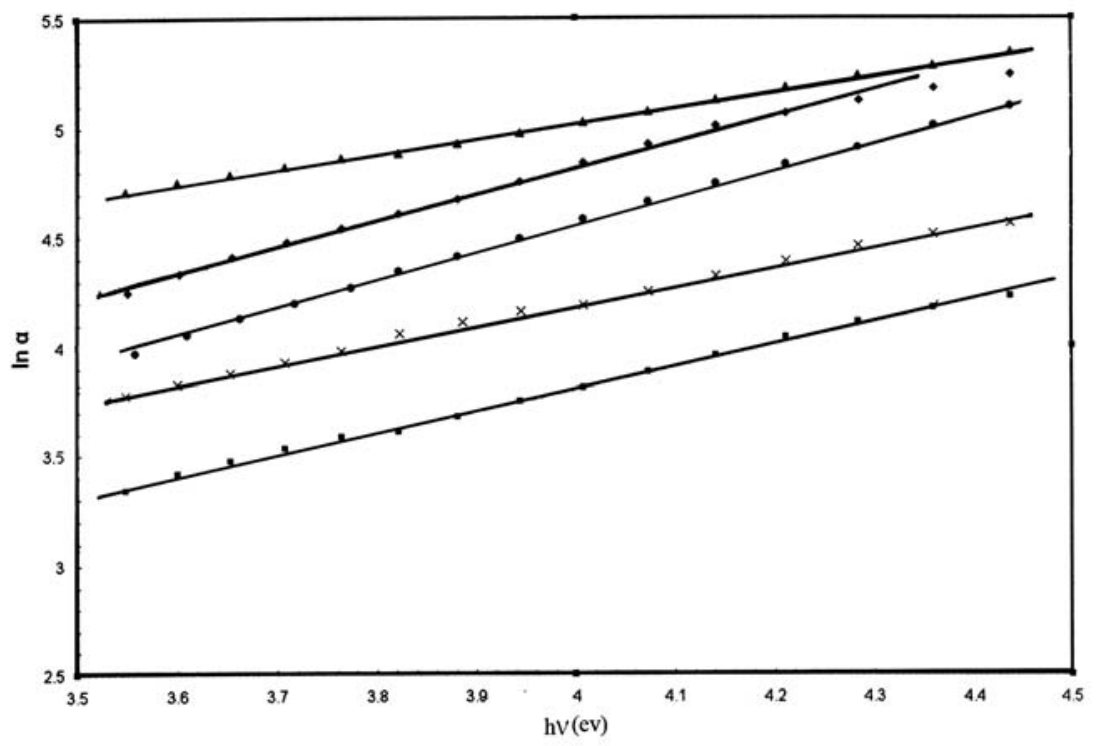

Fig. (10): The relation between $\ln \alpha$ versus ho for PVA/ NaCMC:

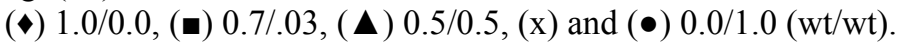

\section{Conclusion:}

In the present work, TGA and DrTG thermal curves show that the thermal properties of PVA/ $\mathrm{NaCMC}$ blend samples are enhanced by increasing $\mathrm{NaCMC}$ content. The thermal stabilities of different samples were confirmed by the corresponding determined activation energies. The decrease of index of crystalline calculated from IR spectra may be assigned to the incorporation of side branches and it is a result of a dilution effect when PVA was blended with NaCMC. From UV/visible studies, it appears that there is an exponential absorption edge in the visible spectral range which could be explained as due to the exponential distribution of the localized states in the normal forbidden gap. The existence of maximum in absorbing edge and minimum in band tail for 0.5/0.5 (wt/wt) PVA/NaCMC blend sample indicate that it has more carrier concentration in the localized levels.

\section{References:}

1. U. W. Gedde. "Polymer Physics "Chepman \& Hall Ch.4 (1995).

2. C. Uma Devi, A.K. Sharma and V.V.R. N.Rao, Materials letters 56, 167 (2002)

3. F.H. AbdelKader, W.H. Osman, H.S. Ragab, A.M. Shehap, M.S. Rizk and M. A. Basha, J. Polym. Matter. 21, 49 (2004). 
4. A. Tawansi, A.Elkhodary and M.M.Abdelnaby, Current Applied Physics 5, 572 (2005).

5. J. Lee, D. Bhttacharryya, A. J. Easteal and J.B. Metson, Current Applied Physics 8, 42 (2008)

6. F. H. Abdel-Kader, A.M. Shehap, M. S. Abellil and K. H. Mahmoud, J. Appl. Polym Sci 95, 1342 (2005).

7. F. H. AbdelKader, A. M. Shehap, M. S. Abellil and K. H. Mahmoud, J. Polym. Matter 22, 349 (2005).

8. H.S. Ragab, M.S. Aboellil, A.M. Shehap and F.H. AbdelKader, J. Appl. Polym Sci. 7, 1748 (2003).

9. K. A. M. AbdelKader, S. F. AbdelHamid, A. B. Mansour and A. M. ELlawindy, J. Polym Testing 21, 847 (2002).

10. J. A. Menjivar, Adv. Chem. Ser. 213, 209 (1986).

11. P. Liu, M. Zhai, J. Li and J. Pengfi, Radiat. Phys. and Chem. 63, 525 (2002).

12. O. H. Lin, R. N Kumr. H. D. Rozmann, M. A. Mnoor, Carbohydrate Polym. 59, 57 (2005).

13. Y. Cao, H. Li, Europian Polym. J. 38, 1457 (2002).

14. H. H. G. Jellinek, J. Polym. Sci. 4, 13 (1949).

15. T. L. Cottrell. 'The Strength of Chemical Bonds", Butterworths, London, p. 275 (1954).

16. A.W. Coats and J. P. Redfern, Nature 201, 68 (1964).

17. F. Yakuphanoglu, A.O. Gorgulu, A. Cukurovali Physica B 353, 223 (2004).

18. J. Li, J. F. Revol and R. H. Marchessault, J. Appl. Polym. Sci. 65, 273 (1998).

19. F. H. Abd El-kader, S. A. Gaafer, M. S. Rizk and N. A. Kamel, J. Appl. Polym. Sci. 72, 1395 (1999).

20. R. Jayasckara, I. Marding, I. Bowater, G. B. Y. Christic and G. T. Lonergan, Polymer Testing, 23 (1), 17 (2004).

21. G. N. Hemantha Kumar, J. Lakshmana Rao, N.O. Goppal, K.V. Narasimhulu, R. P. S. Chakradhar and A. Varada Rajulu, Polymer, 45, 5407 (2004).

22. B. V. K. Naidu, M. Sairam, K.V. S. N. Raju and T. M. Aminabhavi, J. Appl. Polym. Sci.260, 142 (2005).

23. L. Damliac and C. David, Polymer 37, 5219 (1996).

24. M. Tsukada, G. Freddi and J. S. Grighton, J. Polym. Sci., Part B: Polym. Phys., 32, 243 (1994).

25. P. Sakellariou, A. Hassan and R. C. Rowe, Polymer, 34, 1240 (1993).

26. M. Tsukada, G. Freddt and J. S. Crighton J. Polym. Sci. 32, 243 (1994).

27. X. Zhang, K. Takegoshi and K. Hikichi, Polymer 32, 79 (1991).

28. L. Daniliuc and C. David, Polymer 1, 115 (1967). 
29. A. Danno, J. Phys. Sci. Jpn 13, 609 (1958).

30. S. Krimm, C. Y. Liang and G. B. B., M. Sutherland, J. Polym. Sci. 22, 227 (1966).

31. J. F. Kenny and G. W. Willcockson. J. Polym. Sci. A-1 4, 67, (1996).

32. A. Elliot, E. J. Ambrose and R. B. Temple, J. Chem. Phys. 16, 877 (1948).

33. M. Tsukada, G. Freddi and J. S. Crighton. J. Polym. Sci. 32, 243 (1994).

34. D. R.Biswal and R. P. Singh, Carbohydrate Polymers 57, 379 (2004).

35. W. M. Hosny, A. K. Abdel-Hadi, H.El-saied and A. H. Basta, Polymer International, 37, 93 (1995).

36. M. Shibayarna, T. Yamamoto, C. Faxiao, S. Sakurai, A. Hayami and S. Namura, Polymer 32(6), 1010 (1991).

37. F. H. Abd El-kader, S. A. Gaafar, K. H. Mahmoud, S. I. Bannan, M. F. H. Abd El-kader, J. Current Appl. Phys. 8, 78 (2008).

38. F. Urbach, Phys. Rev. 92, 1324 (1952).

39. E. A. Davis and N.F. Mott, Phil. Mag. 22, 903 (1970). 